Check for updates

Cite this: RSC Adv., 2017, 7, 20093

\title{
Synthesis of self-healing waterborne polyurethanes containing sulphonate groups
}

\begin{abstract}
Ye Xiao, Huihua Huang (D) and Xiaohong Peng*
Polyurethanes can be modified to obtain an intrinsic self-healing property, which is the ability to selfrecover from the damage of bulk materials, by changing the ways of increasing the density of hydrogen bonds or by inducing additional reversible crosslinks. An environment-friendly self-healing waterborne polyurethane (SHWPU) containing sulphonate groups was synthesized from isophorone diisocyanate, poly(tetramethylene glycol) and poly(1,4-butylene adipate glycol) and dispersed in water using the aliphatic diamine sulphonate as a hydrophilic chain-extender. The SHWPU coatings show a higher healing efficiency than the coatings without sulphonate group chains extended by ethylenediamine (EDA). With an increase in the soft contents, the healing efficiency increases, by virtue of which the polymer can completely recover itself at a temperature of $100{ }^{\circ} \mathrm{C}$ for $18 \mathrm{~h}$. Moreover, significant phase separation of the continuous soft phase distributed with a spot-like hard phase is observed, which is due

to the formation of ionic clusters.
\end{abstract}

Received 19th December 2016

Accepted 16th March 2017

DOI: 10.1039/c6ra28416g

rsc.li/rsc-advances

\section{Introduction}

Polyurethanes have various applicable properties, such as good processability, versatile structure property relationships and excellent elasticity of their films, which can be obtained by utilizing different types of diols and chainextenders. Polyurethanes extended by amines, which are generally called polyurethane-urea, show superior physical properties compared with diol-extended polyurethanes because of the strong cohesion of urea groups via their hydrogen bonding. ${ }^{1}$ In addition, introduction of hydrophilic extenders, such as 2,2-dimethylolpropionic acid (DMPA), during the pre-polymerization phase can turn polyurethanes from a solvent-based dispersion to a water-based one, which is a remarkable property. Waterborne polyurethanes (WPUs) do not contribute to environmental pollution problems caused by the evaporation of volatile organic compounds during their synthesis and application process; furthermore, they retain the original properties of solvent-type polyurethanes, such as resistance to low temperature, good flexibility, and mechanical properties. ${ }^{2}$ Therefore, WPUs have been widely used for application in several materials, particularly in grouting materials, adhesives, and coatings, which can sustain microdamage very easily. Nowadays, a general approach to obtain a longer lifespan is to develop more resistant properties. Hence, much attention has been paid to the self-healing properties of materials.

School of Material Science and Engineering, South China University of Technology, Guangzhou, Guangdong, People's Republic of China. E-mail: pxhpf@scut.edu.cn; sylvia199209@gmail.com; Fax:+86 2087114799; Tel: +8613668961588
Since the reports on the self-healing concept of materials, ${ }^{3,4}$ more and more researchers utilize this biological property in engineering materials. ${ }^{5-10}$ This approach allows materials to repair themselves automatically after sustaining damage..$^{11,12}$ The self-healing potentials of materials depend strongly on their intrinsic and extrinsic properties. Intrinsic self-healing materials achieve repair through the inherent reversibility of chemical bonds and physical interaction between the damaged interfaces, and extrinsic self-healing materials repair themselves via intentionally pre-embedded healing agents. ${ }^{12}$

The advantages of intrinsic over extrinsic self-healability are the possibility of repairing the initial properties multiple times and better compatibility of the bulk materials containing a reversible molecular structure. The reversible reaction in this structure, including covalent bonds and supramolecular interactions, can be triggered by modest amounts of energy (e.g. light, heat, static load, and $\mathrm{pH}$ variation). ${ }^{11,13-17}$ In addition, a temporary local increase in the mobility of the molecular chains also has a crucial influence on an efficient healing process. ${ }^{18}$

Healable polyurethane is one of the systems that exhibits repairing via supramolecular interaction. In general, the interaction primarily involves hydrogen bonding within numerous urethane and urea groups. However, recently some literatures have reported that more than one type of reversible crosslinks can be introduced in polyurethane to form a multifunctional healing system. ${ }^{19-21}$ Feula et $a l . .^{22}$ synthesized a healable, elastomeric supramolecular polyurethane, which could heal at $45^{\circ} \mathrm{C}$ in 15 min to recover its mechanical properties, resulting from its $\pi-\pi$ stacking and hydrogen bonding interaction. In addition, through small-angle X-ray scattering, a micro- 
separated morphology was observed; it disappeared at $60{ }^{\circ} \mathrm{C}$, indicating that supramolecular network was being disrupted. Sun et al. ${ }^{23}$ developed a mussel-inspired polyurethane adhesive extended by lysine-dopamine; this dopamine-containing sidechain coordinated with $\mathrm{Fe}^{3+}$ to instantaneously form hydrogels that healed through treatment with $\mathrm{NaIO}_{4}$. Thakur et al. ${ }^{24}$ reported that 2-hydroxyethyl disulfide was used as a chain extender to prepare a WPU polymer consisting of disulfide bonds in the main chain. Due to the reversible disulfide bond exchange reaction and the assistance of shape memory owing to hydrogen bonding, the WPUs showed a high healing efficiency at $65{ }^{\circ} \mathrm{C}$ for only $10 \mathrm{~min}$, but the healing process took place above the melting point of the soft segment. Although there are various synthetic methods to build a multifunctional healing system in polyurethanes, reports on self-healing waterborne polyurethane (SHWPU) are very rare.

Herein, an environment-friendly self-healing waterborne polyurethane is synthesized from isophorone diisocyanate and two types of diols, poly(tetramethylene glycol) and poly(1,4butylene adipate glycol). This polyurethane dispersed in water using a sulphonate diamine extender. As shown in Scheme 1, the dual self-healing system contains two types of reversible crosslinks, hydrogen bonding within the hard segment and ionic clusters formed by the sulphonate-containing side chains. The healing process is triggered by raising the temperature to $100{ }^{\circ} \mathrm{C}$ in order to stimulate the reorganization of these crosslinks, and the healing performance is observed through an optical microscope. The stress-strain curves indicate that the SHWPU would have potential applications in self-healing coatings to repair scratches under a readily accessible temperature. Moreover, atomic force microscopy (AFM) and smallangle X-ray scattering (SAXS) are used to investigate the micro-phase separation and ionic interaction, which have an essential influence on the self-healing performance.

\section{Experimental}

\section{Materials}

Poly(tetramethylene glycol) (PTMG, $M_{\mathrm{n}}=1000 \mathrm{~g} \mathrm{~mol}^{-1}$ and $2000 \mathrm{~g} \mathrm{~mol}^{-1}$ ) (Mitsubishi Chemical, Japan) and poly(1,4butylene adipate glycol) (PBA, $M_{\mathrm{n}}=1000 \mathrm{~g} \mathrm{~mol}^{-1}$ ) (Xuchuan Chemicals, China) were dried at $120{ }^{\circ} \mathrm{C}$ under vacuum for $2 \mathrm{~h}$ before use. 2,2-Bis(hydroxymethyl) propionic acid (DMPA) (Mitsubishi Chemical, Japan) was also dried at $50{ }^{\circ} \mathrm{C}$ under vacuum for $48 \mathrm{~h}$ before use. Isophorone diisocyanate (IPDI) (Mitsubishi Chemical, Japan), triethylamine (TEA) (Shanghai Runjie, China), ethylenediamine (EDA) (Tianjin Kaitong, China) and aliphatic diamine sulphonate (ASS, 50\% in aqueous solution) (Tianjin Fuyu, China) were used without purification. Di- $n$ butyldilauryltin (DBTDL) (Aladdin, USA) was used as a catalyst for the pre-polymer synthesis without purification.

\section{Synthesis of self-healing waterborne polyurethane}

The polyurethane prepolymer was synthesized according to the procedure shown in Scheme 1. PTMG, IPDI and the catalyst DBTDL $(0.02 \mathrm{~g})$ were respectively added into a four-necked flask and the reaction mixture was then stirred for $1 \mathrm{~h}$ at $80^{\circ} \mathrm{C}$. After $1 \mathrm{~h}$, PBA was added, and the reaction mixture was stirred until the isocyanate (NCO) content reached a given value, which was based on the fact that all the hydroxyl groups were consumed by NCO groups. After cooling to $70{ }^{\circ} \mathrm{C}$, DMPA was added and the reaction mixture was stirred for another $1 \mathrm{~h}$. The reaction mixture was then added to TEA to neutralize DMPA for $15 \mathrm{~min}$. Emulsification was accomplished by adding a preset amount of distilled water (solid content: $30 \mathrm{wt} \%$ ) to the prepolymer, and then ASS or EDA was added dropwise to the isocyanate terminated prepolymer under vigorous stirring (3000 rpm); after stirring for $30 \mathrm{~min}$, a semitransparent emulsion was the

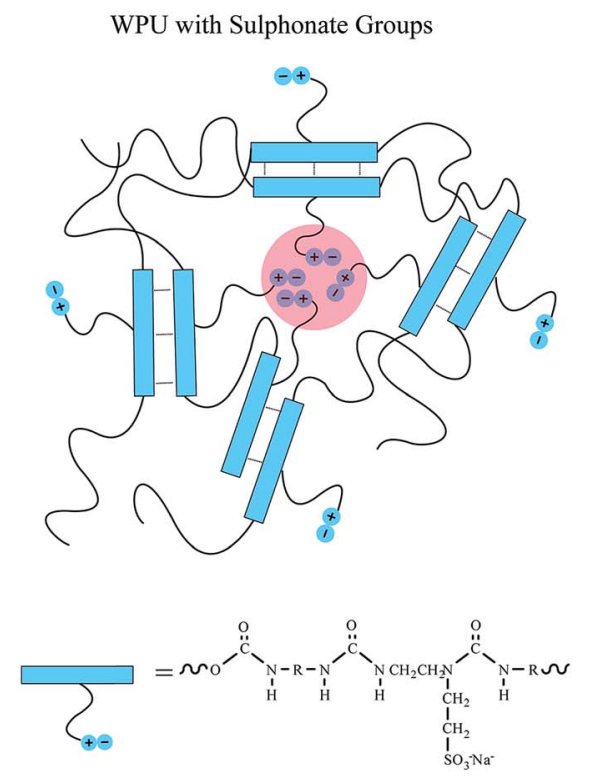

WPU without Sulphonate Groups
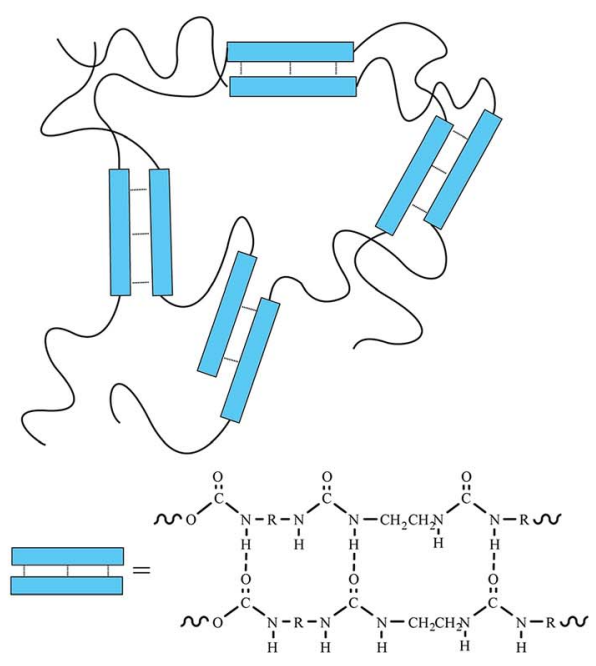

Scheme 1 Comparison of the dual self-healing polyurethane system with sulphonate groups and hydrogen bonds and without sulphonate groups. 
product. WPU films were cast from aqueous dispersions on a Teflon baffle plate and placed in a vacuum at a temperature of $50{ }^{\circ} \mathrm{C}$ for $24 \mathrm{~h}$.

\section{Characterization}

Fourier transform infrared (FTIR) spectra of the prepolymers and WPU films were recorded with a Tensor 27 FTIR analyzer (Bruker Optics, Germany) by averaging 32 scans at a resolution of $2 \mathrm{~cm}^{-1}$ at room temperature. The polyurethane prepolymer solution in acetone was coated onto a piece of $\mathrm{KBr}$ plate, and after evaporating the solvent under vacuum, it was measured in transmission (TR) mode. The WPU films were directly measured in attenuated total reflectance (ATR) mode. ${ }^{1} \mathrm{H}$ nuclear magnetic resonance $\left({ }^{1} \mathrm{H}-\mathrm{NMR}\right)$ spectra were recorded using a $600 \mathrm{MHz}$ spectrometer (Brucker Advance III HD,
Germany), and samples were dissolved in $\mathrm{CDCl}_{3}$ at room temperature. Differential scanning calorimetry (DSC) experiments were carried out using a TA MDSC-2910 instrument with nitrogen as the purge gas. The WPU films were heated from $-20{ }^{\circ} \mathrm{C}$ to $180{ }^{\circ} \mathrm{C}$ at a heating rate of $10{ }^{\circ} \mathrm{C} \mathrm{min}^{-1}$. A polarizing microscope (AndorZyla, British) was used to observe the healing process of the WPU coating finishing of glass slides with an amplification of $10 \mathrm{~cm} \times 10 \mathrm{~cm}$ at $25{ }^{\circ} \mathrm{C}$. The coating was applied to the glass slide surface using a linear rod with firm pressure and kept at $60^{\circ} \mathrm{C}$ in an oven for $1 \mathrm{~h}$. Atomic force microscopy (AFM) (Bruker Multimode 8, Germany) was used to analyze the surface morphology of the WPU films. An etched silicone probe was used in tapping mode with a scanning rate of $1 \mathrm{~Hz}$ to construct phase/height contrast images on the top surface of the sample. Small-

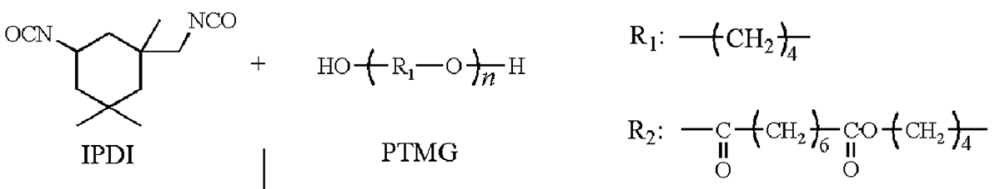

$$
\begin{aligned}
& \text { DBTDL, } 1 \mathrm{~h}, 80^{\circ} \mathrm{C} \\
& \text { OCNN } \\
& \underset{\mathrm{HOA}}{\mathrm{PB}} \underset{\mathrm{R}_{2}-\mathrm{O}+_{m}^{\mathrm{H}}}{ } \downarrow 0.8 \mathrm{~h}, 80^{\circ} \mathrm{C} \\
& \text { OCNN } \\
& \text { (1) } 1 \text { h, } 70^{\circ} \mathrm{C} \quad \stackrel{\mathrm{HOCH}_{2} \mathrm{CCH}_{2} \mathrm{OH}}{\mathrm{COOH}} \\
& \text { (2) } 15 \mathrm{~min}, 50^{\circ} \mathrm{C} \text { TEA }
\end{aligned}
$$

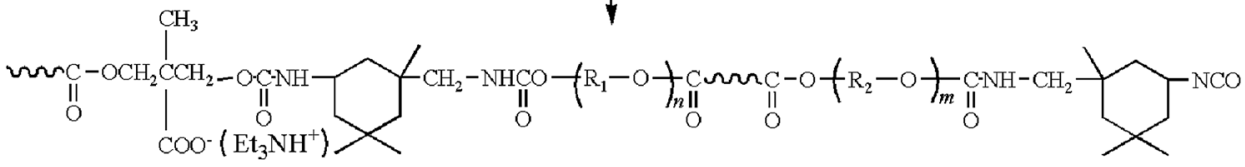

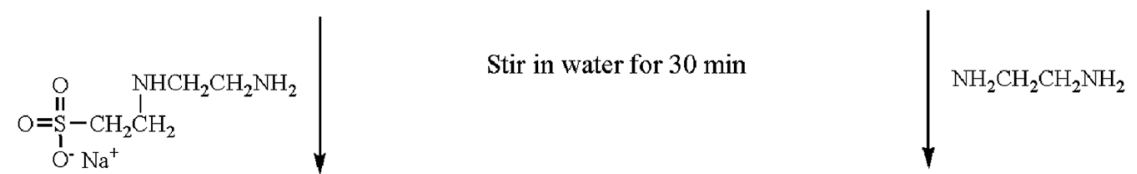

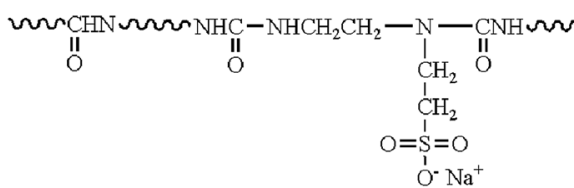

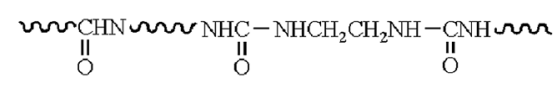

Scheme 2 Synthesis pathway for the self-healing WPUs. 
angle X-ray scattering (SAXS) was conducted using an AXS D8 Advance X-ray diffractometer (Bruker, Germany), equipped with a $\mathrm{Cu}$ anode $\mathrm{X}$-ray tube $(\lambda=0.154 \mathrm{~nm}, 2.2 \mathrm{~kW})$. Tensile tests were conducted using an Intron 5500R electronic universal testing machine. Bone shaped specimens were cut from the sample film with a thickness of $0.5 \mathrm{~mm}$, and the length was $10 \mathrm{~mm}$ in the initial testing status.

\section{Results and discussion}

\section{Synthesis and characterization of polyurethane}

The synthesis pathway of the self-healing waterborne polyurethanes is shown in Scheme 2. They were both synthesized from IPDI with two types of diols (PTMG and PBA), the purpose of which was to form a di-block soft segment, and then extended by DMPA. Since the prepolymer contains carboxyl groups, it can be extended and polymerized in an aqueous system. Furthermore, the NCO-terminated prepolymer reacted with diamine chain-extenders, such as EDA and ASS, after which WPUs with urea groups were obtained. The introduction of urea increases the reversible crosslinking within the polymer formed by hydrogen bonds, which can enhance the healing properties. In addition, in order to investigate the effect of the soft segment contents on self-healing performance and mechanical properties, a series of WPUs with different soft segment contents were prepared. PU- $x \mathrm{U}(x=50$, 60 and 70) was extended by ASS, and PU-50B extended by EDA was used as a control sample to investigate the effect of sulphonate groups on the self-healing performance. These WPU samples were synthesized according to the details given in Table 1.

The FTIR spectra of both the NCO-terminated polyurethane prepolymer and WPUs are outlined in Fig. 1. As seen, the -NCO absorption peak at $2270 \mathrm{~cm}^{-1}$ disappears after the emulsion synthesis. The peaks at 2950 and $2870 \mathrm{~cm}^{-1}$ are associated with the symmetric and asymmetric stretching vibration modes of the $\mathrm{C}-\mathrm{H}$ bonds. The peaks at $1705 \mathrm{~cm}^{-1}$ and $1535 \mathrm{~cm}^{-1}$ correspond to the stretching vibration modes of both the $\mathrm{C}=\mathrm{O}$ and $\mathrm{N}-\mathrm{H}$ bonds in the urethane groups, respectively. In addition, the broad absorption band of the $\mathrm{N}-\mathrm{H}$ stretching vibration at around $3370 \mathrm{~cm}^{-1}$ in the WPU polymer indicates the generation of -NHCOHN- groups and numerous hydrogen bonds.

The ${ }^{1} \mathrm{H}$-NMR spectra of the WPUs are shown in Fig. 2. The $\mathrm{H}$ signals at $7.09 \mathrm{ppm}$ and $6.96 \mathrm{ppm}$ observed are assigned to urethane (-NH-CO-O-) and urea (-NH-CO-N-) groups, respectively. The integrals of the peaks (dash area shown in

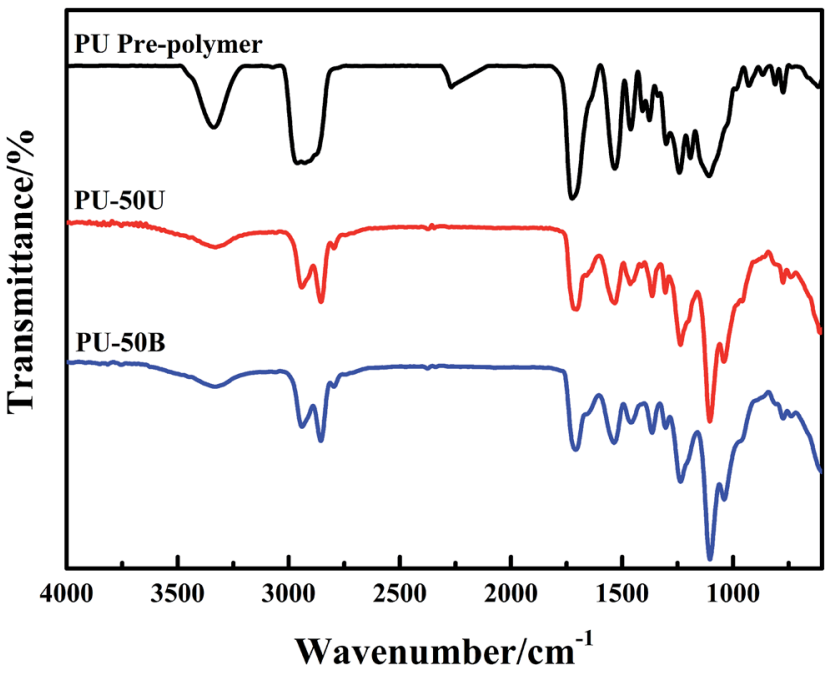

Fig. 1 FTIR spectra of the PU prepolymer, PU-50U, and PU-50B.

Fig. 2) show the corresponding ratio to the calculated values ( $1: 0.45,1: 0.29,1: 0.26$ and $1: 0.61$ ). These results and FTIR analysis provide direct evidence that the reaction between -NCO and diamine was complete, and WPUs were successfully synthesized. ${ }^{1} \mathrm{H}-\mathrm{NMR}\left(\mathrm{CDCl}_{3}, 600 \mathrm{MHz}\right): \delta 2.91(\mathrm{~s}, 2 \mathrm{H},-\mathrm{NH}-$ $\mathrm{CH}_{2}$ of IPDI), $\delta 1.06\left(\mathrm{~s}, 6 \mathrm{H},-\mathrm{C}\left(\mathrm{CH}_{3}\right)_{2}\right.$ of IPDI), $\delta 1.62(\mathrm{~m}, 4 \mathrm{H}$, $-\mathrm{CH}_{2}$ of PTMG), $\delta 3.41$ (s, 4H, $-\mathrm{CH}_{2}$ of PTMG), $\delta 2.26(\mathrm{~s}, 4 \mathrm{H}$, $\mathrm{CO}-\mathrm{CH}_{2}$ of PBA), $\delta 4.09$ (t, $4 \mathrm{H}, \mathrm{COO}-\mathrm{CH}_{2}$ of PBA), $\delta 4.06(\mathrm{~d}, 2 \mathrm{H}$, $-\mathrm{COO}-\mathrm{CH}_{2}$ of DMPA), $\delta 0.88\left(\mathrm{~s}, 3 \mathrm{H},-\mathrm{CH}_{3}\right.$ of DMPA), $\delta 1.18-$

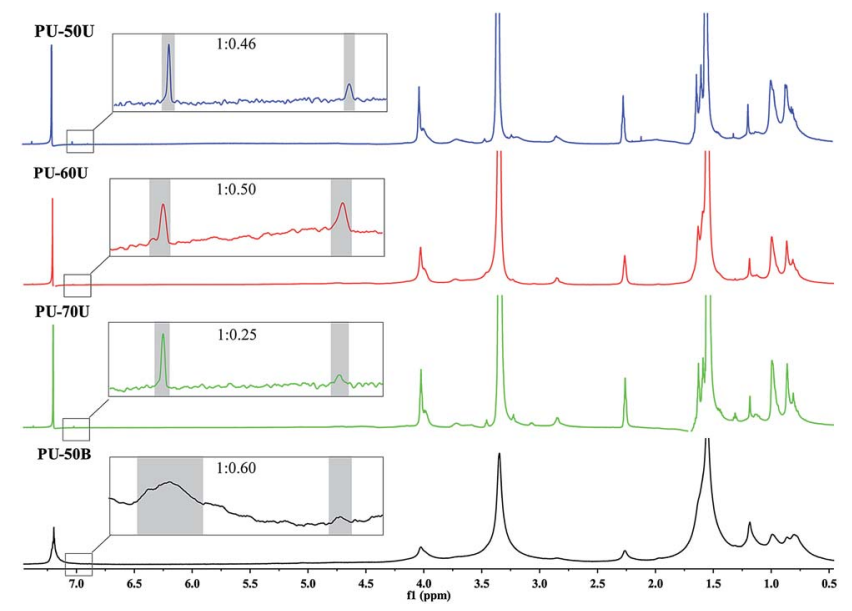

Fig. $2{ }^{1} \mathrm{H}$-NMR spectra of the pure WPUs.

Table 1 Compositions of the self-healing WPUs with different soft segment contents and extenders

\begin{tabular}{|c|c|c|c|c|c|c|c|c|}
\hline \multirow[b]{2}{*}{ Sample code } & \multicolumn{8}{|c|}{ Reactant/wt\% } \\
\hline & IPDI & PTMG1000 & PTMG2000 & PBA & DMPA & ASS & EDA & Soft segment \\
\hline PU-50U & 28.6 & 40.8 & - & 10.7 & 4.0 & 12.7 & - & 50 \\
\hline PU-60U & 25.3 & 49.3 & - & 9.5 & 3.6 & 9.7 & - & 60 \\
\hline PU-70U & 18.8 & - & 61.9 & 7.0 & 3.6 & 6.1 & - & 70 \\
\hline PU-50B & 36.0 & 43.2 & - & 8.1 & 4.7 & - & 4.5 & 50 \\
\hline
\end{tabular}




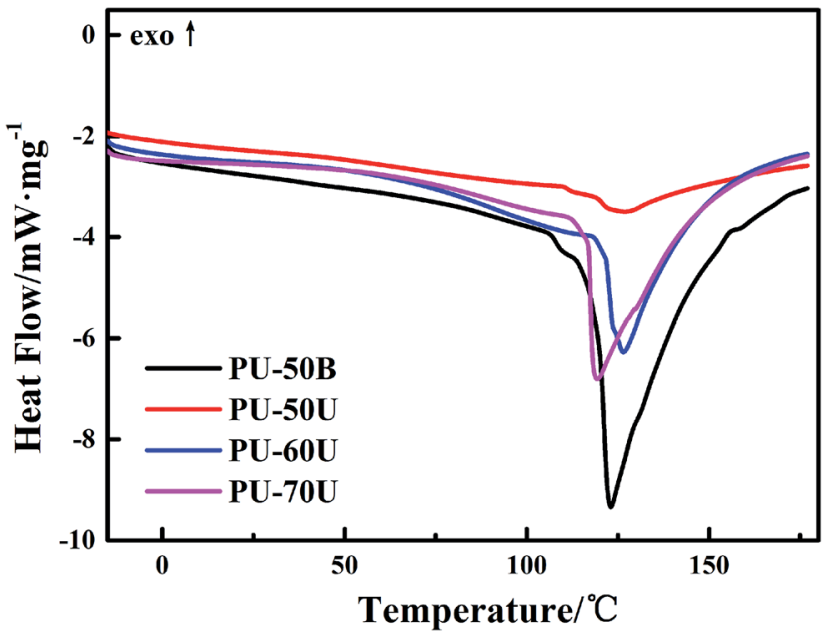

Fig. 3 DSC curves of the WPUs.

$1.26\left(\mathrm{~s}, 2 \mathrm{H},-\mathrm{NH}-\mathrm{CH}_{2}\right.$ of EDA or AAS $), \delta 1.50\left(\mathrm{~m}, 2 \mathrm{H},-\mathrm{CH}_{2}\right.$ of AAS).

The DSC curves shown in Fig. 3 were used to investigate the effect of different structures and soft segment contents on the melting behaviors and crystallization of the WPUs. The melting temperature $\left(T_{\mathrm{m}}\right)$ of the different WPUs is from $123^{\circ} \mathrm{C}$ to $126^{\circ} \mathrm{C}$ without significant discrepancies. In particular, PU-50B has the largest area of endothermic melting peaks among the PU- $x \mathrm{U}$, which reveals that it has the highest degree of crystallinity. This result demonstrates that the EDA-extended polymer has a more orderly arranged molecular structure than the AAS polymers since the pendant sulphonate groups in PU- $x \mathrm{U}$ could break the regular arrangement of the hard segment. In addition, it can be observed in PU- $x$ U that the degree of crystallinity increases with a decrease in the sulphonate mass fraction from $12.7 \%$ to $6.1 \%$ according to Table 1 .

\section{Self-healing properties}

Before the microscope images were taken, the coatings were scratched thoroughly by a fresh bistoury to generate a small crack. Then, all the samples were kept in an oven at $100{ }^{\circ} \mathrm{C}$ for $18 \mathrm{~h}$ in order to investigate their thermal healing properties below $T_{\mathrm{m}}\left(123-126^{\circ} \mathrm{C}\right)$ without polymeric melting. After cooling to room temperature, the healing cracks were observed under a microscope. The images of the scratched and healed PU-50B, PU-50U, PU-60U, and PU-70U coatings are shown in Fig. 4. It can be seen that the cracks within PU-50B remained essentially unchanged and those within PU-50U were partially closed, whereas the damaged PU-60U and PU-70U almost turned to a homogeneous material with only a slight mismatch interface, which suggests a remarkable self-healing efficiency with the increase in soft segment contents. Although the increase in soft segment contents might reduce the density of hydrogen bonds, the interaction of the sulphonate groups and the flexibility of the polymer chain are considered as essential factors for the healing efficiency. Reversible hydrogen bonds provide a good basis for micrometer-scale deformation recovery (shape memory effect), whereas ionic interaction is good for nanoscale healing; ${ }^{25}$ thus PU- $x \mathrm{U}$ has a better healing performance than the pure ionic healing systems. ${ }^{26,27,29}$

AFM provides a powerful tool to visually investigate the morphology of the WPU films. As shown in Fig. 5, the 3D phase/ height contrast images of the WPU surface were observed by AFM analysis. The phase images map the distribution of the WPUs with different hardness, which appears as a continuous soft phase with a spot-like hard phase distribution in PU-50U and PU-60U. These spots have an average size of $40 \mathrm{~nm}$. In addition, in the surface topography of the WPU films, the same distribution and average size of spot-like bulges appear in the height contrast images. However, the phase image of PU-50B, which also consists of numerous urea groups, shows a homogeneous, non spot-like phase distribution. This result

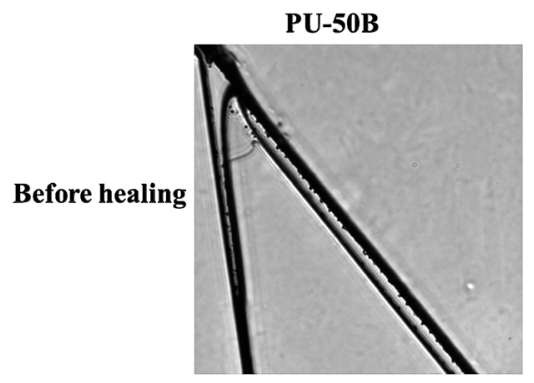

PU-50B

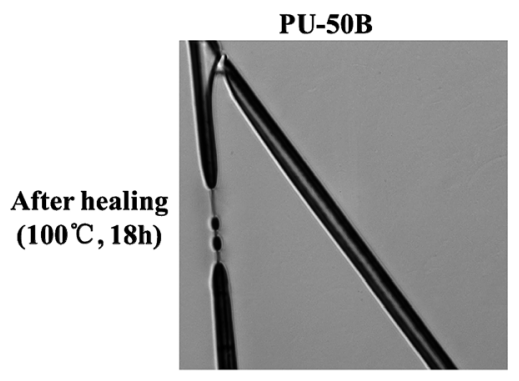

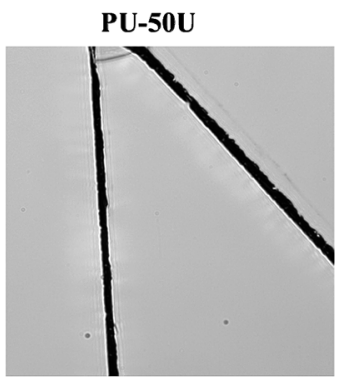

PU-50U

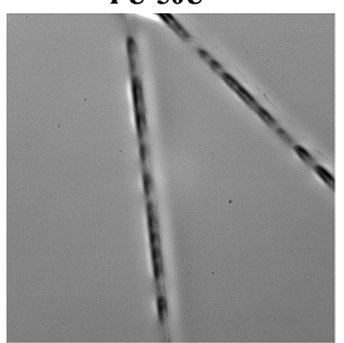

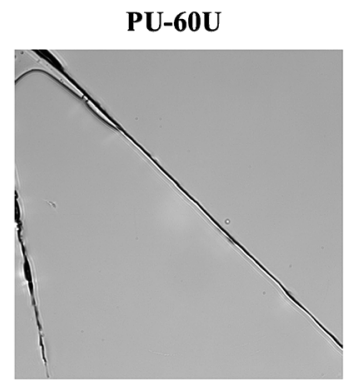

PU-60U

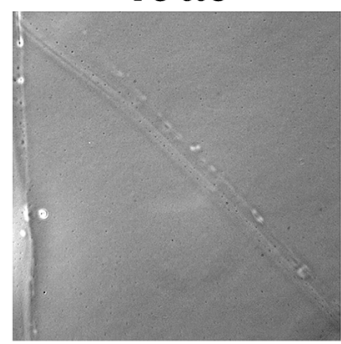

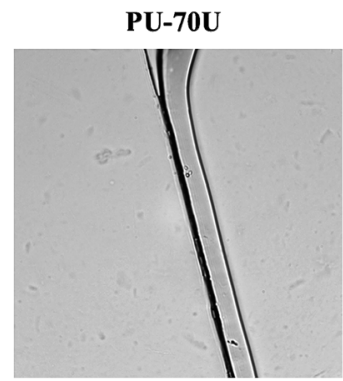

PU-70U

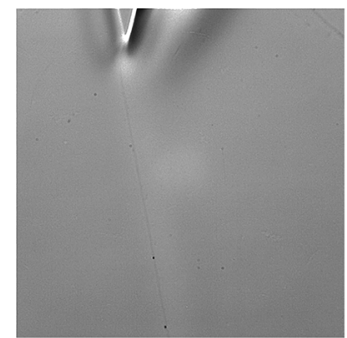

Fig. 4 Optical microscope images of PU-50B, PU-50U, PU-60U, and PU-70U before healing and after healing (100 $\left.{ }^{\circ} \mathrm{C}, 18 \mathrm{~h}\right)$. 


\section{PU-50B}

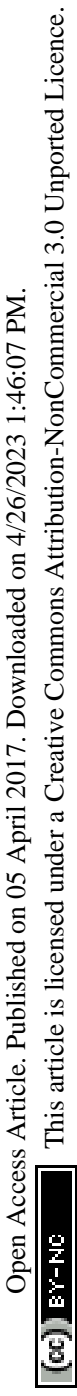

Phase

PU-50U

Phase

\section{PU-60U}
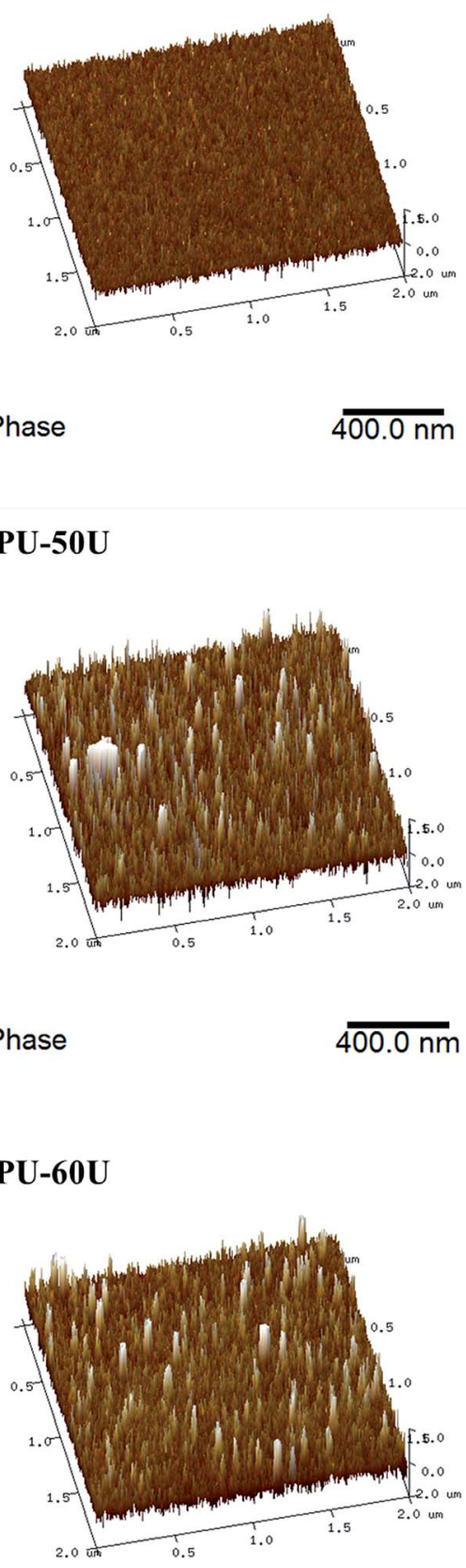

Phase
$4 \overline{00.0 \mathrm{~nm}}$

$4 \overline{00.0 \mathrm{~nm}}$
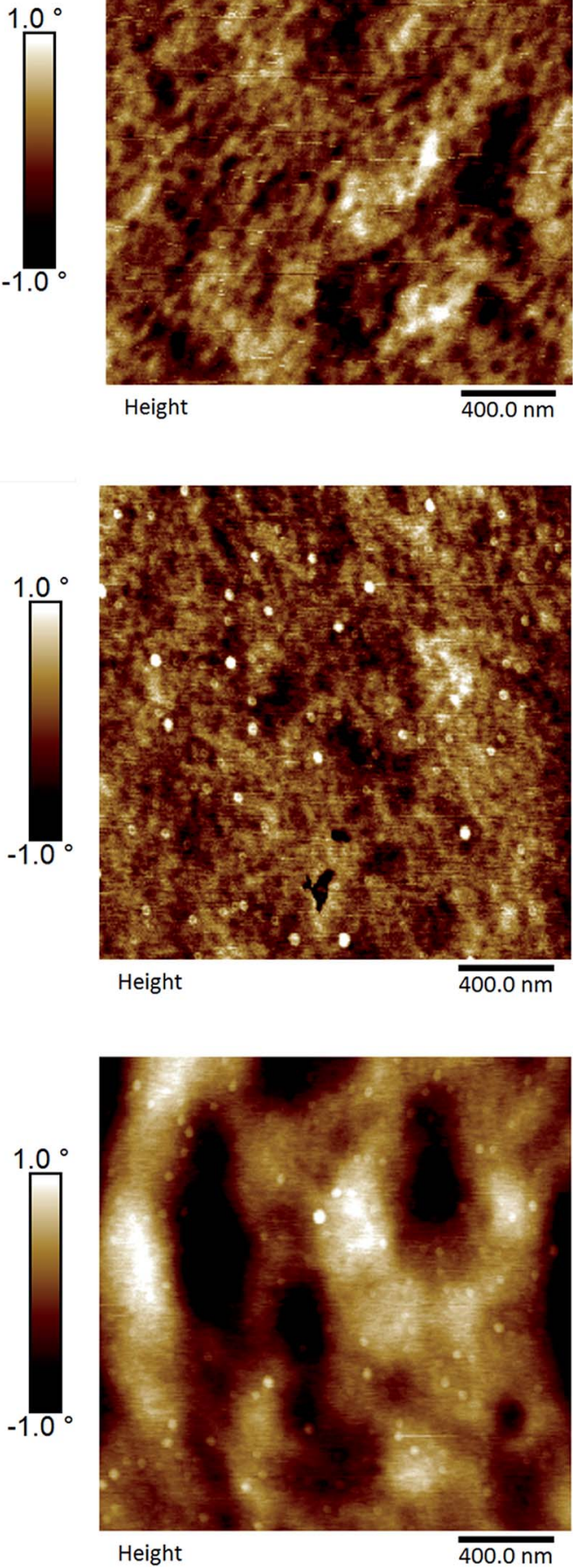
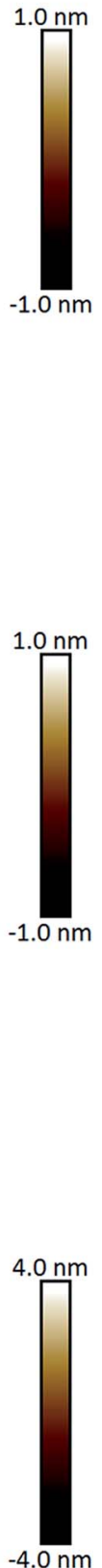

Fig. 5 Phase/height contrast images obtained for PU-50B, PU-50U, and PU-60U.

indicates that the sulphonate groups have a significant effect on the microphase separation of the WPU films and their healing performance.

SAXS measurements were also conducted on these samples to investigate the polymer morphology. As shown in Fig. 6, the SAXS curves of both PU-50U and PU-60U present a broad peak in the $2 \theta$ range of $0.80-0.97^{\circ}$ and double peaks at $1.42-1.67^{\circ}$, whereas the PU-50B curve shows no evident scattering peak in these ranges. The scattering peaks result from the typical hard-segment inter-domain spacing in the samples. Based on the Bragg equation, the domain spacing $d=\lambda / 2 \sin \theta_{\max }$, where $\theta_{\max }$ corresponds to the scattering peak maximum, thus PU-50U and PU-60U have the two feature sizes of $10 \mathrm{~nm}$ and $6 \mathrm{~nm}$. The SAXS and AFM results are in good agreement in terms of the microphase separation morphology. According to Varley and Zwaag's assumption, healing behavior based on 


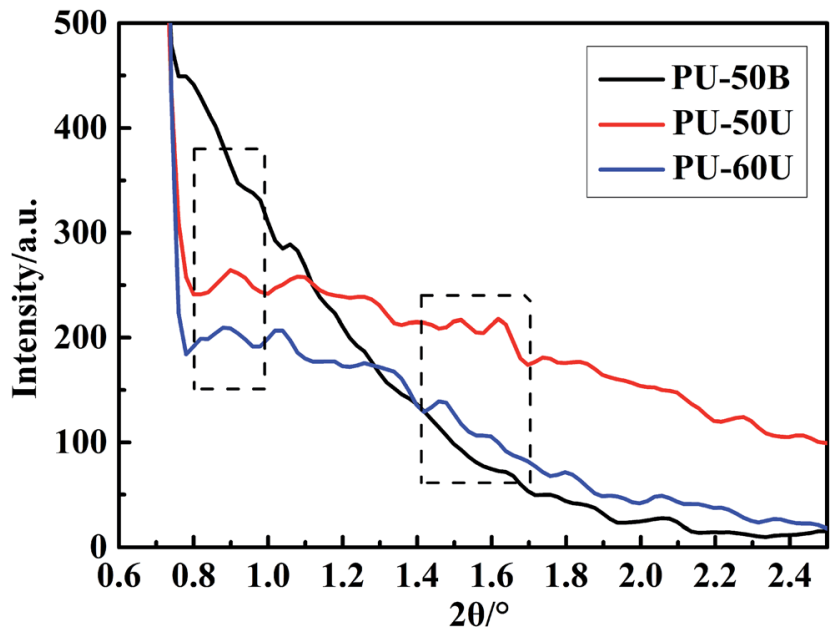

Fig. 6 SAXS patterns observed for PU-50B, PU-50U and PU-60U.

ionic interactions is due to the generation of ionic clusters, from which the scattering peaks derive. ${ }^{28,29}$ Besides, PU-60U has a slight increment in $d$ value due to the left shift of $2 \theta$, which indicates a larger cluster size than PU-50U. ${ }^{30}$ This phenomenon strongly depends on the flexibility of the polymer backbone. ${ }^{29,31}$ This is the reason why the increase in the soft segment contents contributes to the self-healing performances.

\section{Mechanical properties of the WPU films}

The tensile testing results of the different WPU films are summarized in Table 2 and the stress-strain curves are displayed in Fig. 7. It is clear that the polymer structure strongly influences mechanical properties. The PU-50B sample has the highest tensile strength $\left(\sigma_{\mathrm{m}}\right)$ of $61.63 \mathrm{MPa}$ due to its high degree of crystallinity, whereas the PU- $x \mathrm{U}(x=50,60$ and 70) samples have higher breaking elongation rates $\left(\varepsilon_{\mathrm{m}}\right)$ ranging from $512.36 \%$ to $836.76 \%$. Furthermore, the breaking elongation rate increased with an increase in the soft segment content in PU- $x \mathrm{U}$, which indicates an increment of chain flexibility. Compared with the self-healing test results above, PU- $x \mathrm{U}$, particularly PU-70U, has the most outstanding healing performance. Thus, it can be confirmed that polymeric chain flexibility is a determining factor for its self-healing performance. However, as the tensile strain increases, the tensile strength of the WPU films decreases according to the data shown in Table 2. Thus, PU-60U may have potential application in functional coatings.

Table 2 Mechanical data of the different WPU films

\begin{tabular}{lcc}
\hline Sample code & $\sigma_{\mathrm{m}}(\mathrm{MPa})$ & $\varepsilon_{\mathrm{m}}(\%)$ \\
\hline PU-50B & 61.63 & 310.01 \\
PU-50U & 7.90 & 512.36 \\
PU-60U & 8.57 & 700.84 \\
PU-70U & 3.30 & 836.76
\end{tabular}

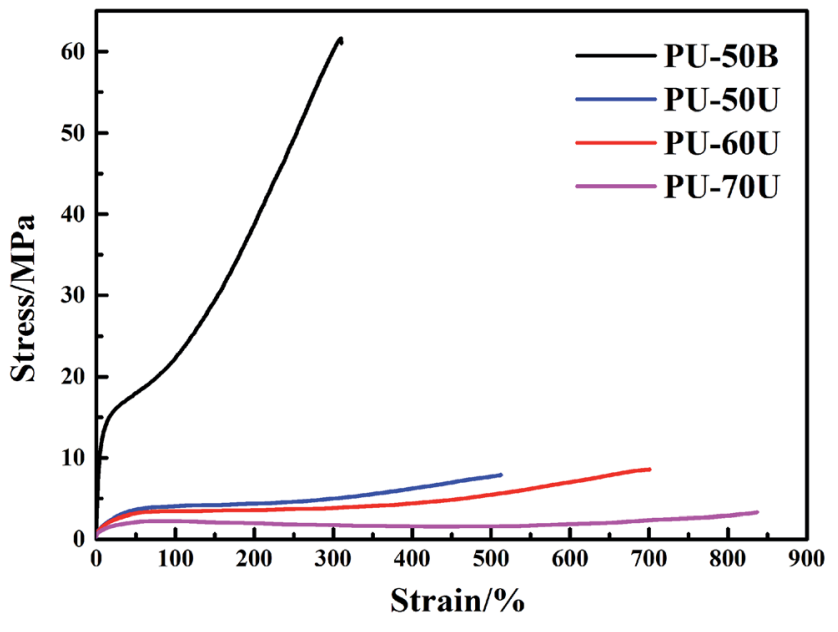

Fig. 7 Stress-strain curves of the different WPU films.

\section{Conclusion}

Herein, a series of SHWPU containing sulphonate groups with different soft segment contents were successfully synthesized. Comparing these SHWPU with respect to thermal and mechanical properties, healing efficiency, and surface morphology, we draw the following conclusions: (1) the SHWPUs with a similar $T_{\mathrm{m}}$ of $123-126{ }^{\circ} \mathrm{C}$ can be triggered to heal themselves entirely at $100{ }^{\circ} \mathrm{C}$ below the $T_{\mathrm{m}}$ for $18 \mathrm{~h}$, which indicates no polymeric melting during the healing process. (2) PU- $x \mathrm{U}(x=50,60$, and 70$)$ extended by sulphonate diamine shows a higher healing efficiency than the EDA-extended PU50B. With an increase in soft contents, the healing efficiency of the PU- $x \mathrm{U}$ films increases. (3) Only the PU- $x \mathrm{U}$ films show a microphase separation structure for the surface topography, and SAXS analysis confirms that the spot-like hard phase distribution is due to the formation of ionic clusters, which is an important factor for self-healing. (4) The PU-50B film has the highest tensile strength of 61.63 MPa due to its high degree of crystallinity, whereas the PU-60U film has an excellent breaking elongation rate of $700.84 \%$; thus the latter may have potential application in functional coatings.

\section{Acknowledgements}

This study was financially supported by Science and Technology Planning Project of Guangdong Province, China (Grant No. 2014A010105019).

\section{References}

1 R. Stadler and L. D. L. Freitas, Colloid Polym. Sci., 1986, 264, 773-778.

2 T. Wan and D. Chen, J. Mater. Sci., 2016, 52, 1-11.

3 C. M. Dry, Smart Mater. Struct., 1994, 3, 118-123.

4 S. R. White, N. R. Sottos, P. H. Geubelle, J. S. Moore, M. R. Kessler, S. R. Sriram, E. N. Brown and S. Viswanathan, Nature, 2001, 409, 794-797. 
5 R. P. Sijbesma, F. H. Beijer, L. Brunsveld, B. J. B. Folmer, J. H. K. K. Hirschberg, R. F. M. Lange, J. K. L. Lowe and E. W. Meijer, ChemInform Abstract: Reversible Polymers Formed from Self-Complementary Monomers Using Quadruple Hydrogen Bonding, 2010.

6 A. Stankiewicz, I. Szczygieł and B. Szczygieł, J. Mater. Sci., 2013, 48, 8041-8051.

7 P. Cordier, F. Tournilhac, C. Soulié-Ziakovic and L. Leibler, Nature, 2008, 451, 977-980.

8 N. Hohlbein, A. Shaaban, A. R. Bras, W. Pyckhouthintzen and A. M. Schmidt, Phys. Chem. Chem. Phys., 2015, 17, 21005-21017.

9 Y. Wu, L. Wang, X. Zhao, S. Hou, B. Guo and P. X. Ma, Biomaterials, 2016, 104, 18-31.

10 D. Palin, V. Wiktor and H. M. Jonkers, Smart Mater. Struct., 2016, 25, 084008.

11 Y. J. Kim, P. H. Huh and B. K. Kim, J. Polym. Sci., Part B: Polym. Phys., 2014, 53, 468-474.

12 M. Q. Zhang and M. Z. Rong, 4. Extrinsic Self-Healing via Cationic Polymerization, John Wiley \& Sons, Inc., 2011.

13 A. Feula, X. Tang, I. Giannakopoulos, A. M. Chippindale, I. W. Hamley, F. Greco, C. P. Buckley, C. R. Siviour and W. Hayes, Chem. Sci., 2016, 7, 4291-4300.

14 Q. Zheng, Z. Ma and S. Gong, J. Mater. Chem. A, 2016, 4, 3324-3334.

15 M. W. Urban, Prog. Polym. Sci., 2009, 34, 679-687.

16 S. J. Kalista, J. R. Pflug and R. J. Varley, Polym. Chem., 2013, 4, 4910-4926.

17 V. Yesilyurt, M. J. Webber, E. A. Appel, C. Godwin, R. Langer and D. G. Anderson, Adv. Mater., 2016, 28, 3402.
18 S. J. Garcia, Eur. Polym. J., 2014, 53, 118-125.

19 G. Fu, L. Yuan, G. Liang and A. Gu, J. Mater. Chem. A, 2016, 4, 4232-4241.

20 J. J. Cash, T. Kubo, A. P. Bapat and B. S. Sumerlin, Macromolecules, 2015, 48, 2098-2106.

21 S. Chen, Z. Mei, H. Ren, H. Zhuo, J. Liu and Z. Ge, Polym. Chem., 2016, 7, 5773-5782.

22 A. Feula, A. Pethybridge, I. Giannakopoulos, X. Tang, A. Chippindale, C. R. Siviour, C. P. Buckley, I. W. Hamley and W. Hayes, Macromolecules, 2015, 48, 6132-6141.

23 P. Sun, J. Wang, X. Yao, Y. Peng, X. Tu, P. Du, Z. Zheng and X. Wang, ACS Appl. Mater. Interfaces, 2014, 6, 12495-12504.

24 S. Thakur and N. Karak, J. Mater. Chem., 2015, 3, 1233412342.

25 B. Ghosh, C. C. Corten and M. W. Urban, Self-Repairing Polymeric Materials, 2011.

26 R. J. Varley and S. V. D. Zwaag, Acta Mater., 2008, 56, 57375750.

27 Z. Wang, W. Fan, R. Tong, X. Lu and H. Xia, RSC Adv., 2014, 4, 25486-25493.

28 R. J. Varley and S. V. D. Zwaag, Polym. Test., 2008, 27, 11-19. 29 S. Bode, L. Zedler, F. H. Schacher, B. Dietzek, M. Schmitt, J. Popp, M. D. Hager and U. S. Schubert, Adv. Mater., 2013, 25, 1634-1638.

30 K. H. Ko, M. Luqman, Y. W. Kim and J. S. Kim, J. Polym. Sci., Part B: Polym. Phys., 2016, 54, 1043-1053.

31 D. Döhler, H. Peterlik and W. H. Binder, Polymer, 2015, 69, 264-273. 